\title{
Size of seismic tensile strain and its influence on the lateral buckling of highly reinforced concrete walls
}

\author{
Theodoros A. Chrysanidis ${ }^{1}$ \\ ${ }^{I}$ Department of Civil Engineering, Aristotle University of Thessaloniki, Greece
}

\begin{abstract}
The current work investigates one of the most basic parameters affecting the stability of structural walls, which is (apart from the wall thickness) the degree of tensile strain of the longitudinal reinforcement of the boundary edges of load-bearing walls. The present work is experimental and in its framework, 5 test specimens of scale 1:3 simulating the boundary edges of structural walls were used. These specimens were reinforced with the same amount of reinforcement equal to a high longitudinal reinforcement ratio (3.68\%). The degree of tensile strain applied was different for each specimen and it took values equal to $0 \%$, $10 \%$, 20\%, $30 \%$ and $50 \%$. The present research work tries to investigate the influence of the degree of tensile strain to the ultimate bearing capacity of walls using test specimens detailed with a high longitudinal reinforcement ratio.

Keywords: Lateral instability, High reinforcement ratio, Structural walls, Tensile strain
\end{abstract}

\section{INTRODUCTION}

Seismic design of reinforced concrete buildings usually utilizes a number of sufficient structural walls. Buildings with a large number of structural walls have demonstrated exceptional behaviour against seismic action, even if these walls had not been reinforced according to the modern perceptions [1]. Structural walls designed to be in a high ductility category according to modern international codes such as EC8: 2004 [2] and NZS 3101: 2006 [3] or were designed with increased ductility requirements according to E.K.S.L. 2000 (Greek Concrete Code 2000) [4], are expected to present extensive tensile deformations, especially in the plastic hinge region of their base. According to Chai and Elayer [5], tensile deformations up to 30\% are expected at the walls of the bottom storey height depending on their geometric characteristics and the level of ductility design of the walls. These tensile deformations, depending on their size, can cause out-of-plane buckling of walls. Prominent researchers [6] propose the use of flanges or enlarged boundary elements in the extreme regions of walls, which provide protection to the bending compression regions against transverse instability. Moreover, these elements are easier to be confined. New Zealand Concrete Code (NZS 3101: 2006) [3] and other modern international codes propose the construction of such elements. The phenomenon of lateral buckling of $\mathrm{R} / \mathrm{C}$ walls depends basically on the size of tensile deformations which are imposed at the extreme regions of walls at the first semicycle of seismic loading and not so much on the size of flexural compression which is imposed at the reversal of seismic loading [7].

Initial work on the same subject has been conducted by the author of the present work collaborating with other researchers $[8,9]$. Later on, the progress of research revealed new results [10]. The present paper presents the new results focusing on walls reinforced (at their boundary edges) with a high longitudinal reinforcement ratio and on the way that factor of tensile strain influences their ultimate bearing capacity. It has to be noted the fact that the terms lateral, transverse and out-of-plane are used herein to describe the same phenomenon, meaning the out-of-plane instability of $\mathrm{R} / \mathrm{C}$ seismic walls. The present work on the phenomenon of out-of-plane buckling constitutes a small part of an extensive research program that took place at the Laboratory of Reinforced Concrete and Masonry Structures of the Department of Civil Engineering of the School of Engineering of Aristotle University of Thessaloniki. The conduction of all experiments took place at the Laboratory of Experimental Strength of Materials and Structures of the Department of Civil Engineering of the School of Engineering of Aristotle University of Thessaloniki.

\subsection{Test specimen characteristics}

\section{EXPERIMENTAL INVESTIGATION}

The test specimens were constructed using the scale 1:3 as a scale of construction. The dimensions of specimens are equal to $7.5 \times 15 \times 90 \mathrm{~cm}$. The reinforcement of specimens is constituted by six bars. Four bars have a diameter of $10 \mathrm{~mm}$ and 2 bars have a diameter of $8 \mathrm{~mm}$. The total number of specimens is equal to 5 . Each specimen was submitted first in uniaxial tensile loading up to a specific and preselected degree of elongation and then was strained under central compression loading. The differentiation of specimens lies in the different degree of elongation that was imposed in each one of them. The specimen characteristics are brought together in Table 1, while Fig. 1 presents a sketch of the front view of specimens both for tensile and compressive loading. As far as specimens strained under compressive loading are concerned, there was a need 
for the construction of a cube at each end of the specimen in order to be able to apply the compressive load. This cube had dimensions 20x20x20 cm and it is called "Shoe". It is noted (because it is not given in Table 1) that steel bar yield resistance for $8 \mathrm{~mm}$ diameter bars is equal to $603.77 \mathrm{MPa}$ and for $10 \mathrm{~mm}$ diameter bars is equal to $552.02 \mathrm{MPa}$. It has to be clarified that the terms degree of elongation and degree of tensile strain refer to the same thing, which is the amount of residual tensile strain that has been imposed to the specimens after the completion of the first semi-cycle of loading (meaning after the end of the uniaxial tension test).

Table 1: Test specimens' characteristics

\begin{tabular}{|c|c|c|c|c|c|c|c|}
\hline N/A & $\begin{array}{l}\text { Description of } \\
\text { specimens }\end{array}$ & $\begin{array}{l}\text { Dimensions } \\
(\mathrm{cm})\end{array}$ & $\begin{array}{l}\text { Longitudinal } \\
\text { reinforcement }\end{array}$ & $\begin{array}{l}\text { Transverse } \\
\text { reinforcement }\end{array}$ & $\begin{array}{l}\text { Longitudinal } \\
\text { reinforcement } \\
\text { ratio } \\
(\%)\end{array}$ & $\begin{array}{l}\text { Concrete cube } \\
\text { resistance at day of } \\
\text { compression test } \\
(\mathrm{MPa})\end{array}$ & $\begin{array}{l}\text { Degree of } \\
\text { elongation } \\
(\% \text { ) }\end{array}$ \\
\hline 1 & Y-4Ø10+2Ø8-368-0-1 & $15 \times 7.5 \times 90$ & $4 \varnothing 10+2 \varnothing 8$ & $\varnothing 4.2 / 3.3 \mathrm{~cm}$ & 3.68 & 25.78 & 0.00 \\
\hline 2 & Y-4Ø10+2Ø8-368-0-2 & $15 \times 7.5 \times 90$ & $4 \varnothing 10+2 \varnothing 8$ & $\varnothing 4.2 / 3.3 \mathrm{~cm}$ & 3.68 & 25.78 & 10.00 \\
\hline 3 & Y-4Ø10+2Ø8-368-0-3 & $15 \times 7.5 \times 90$ & $4 \varnothing 10+2 \varnothing 8$ & $\emptyset 4.2 / 3.3 \mathrm{~cm}$ & 3.68 & 25.78 & 20.00 \\
\hline 4 & Y-4Ø10+2Ø8-368-0-4 & $15 \times 7.5 \times 90$ & $4 \varnothing 10+2 \varnothing 8$ & $\varnothing 4.2 / 3.3 \mathrm{~cm}$ & 3.68 & 25.78 & 30.00 \\
\hline 5 & Y-4Ø10+2Ø8-368-0-5 & $15 \times 7.5 \times 90$ & $4 \varnothing 10+2 \varnothing 8$ & $\emptyset 4.2 / 3.3 \mathrm{~cm}$ & 3.68 & 25.78 & 50.00 \\
\hline
\end{tabular}

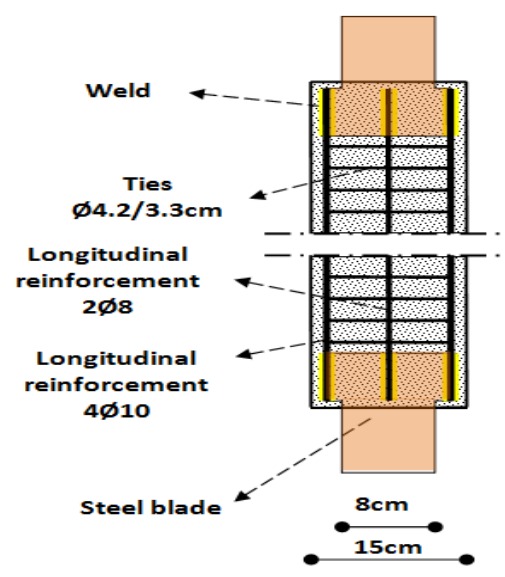

(a)
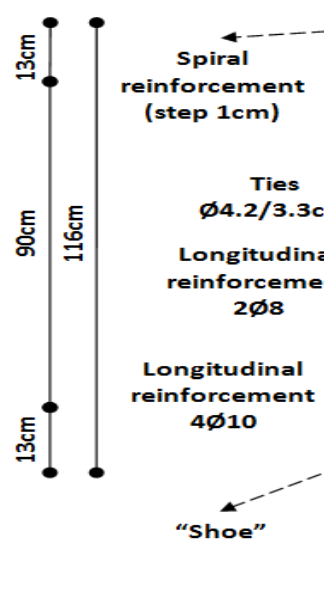

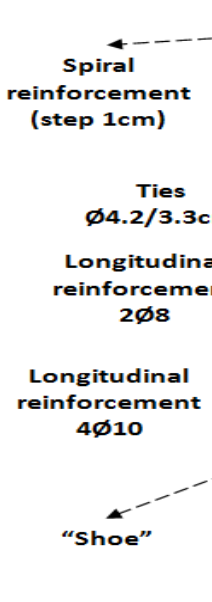

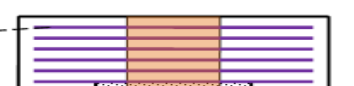

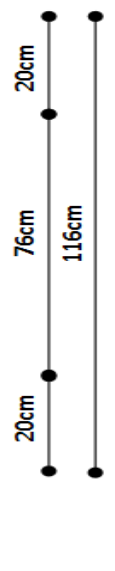

(b)

Figure 1: Sketch of front view of specimens having longitudinal reinforcement $4 \varnothing 10+2 \varnothing 8$ for: (a) Tension, (b) Compression

\subsection{Loading of specimens}

The experimental setups that were used to impose on the specimens the uniaxial tensile load in the first semi-cycle of loading and the concentric compressive load in the second semi-cycle of loading are presented in Fig. 2.

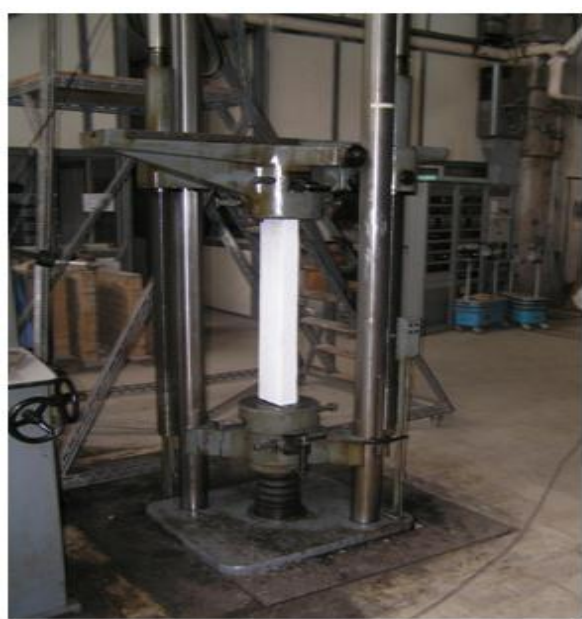

(a)

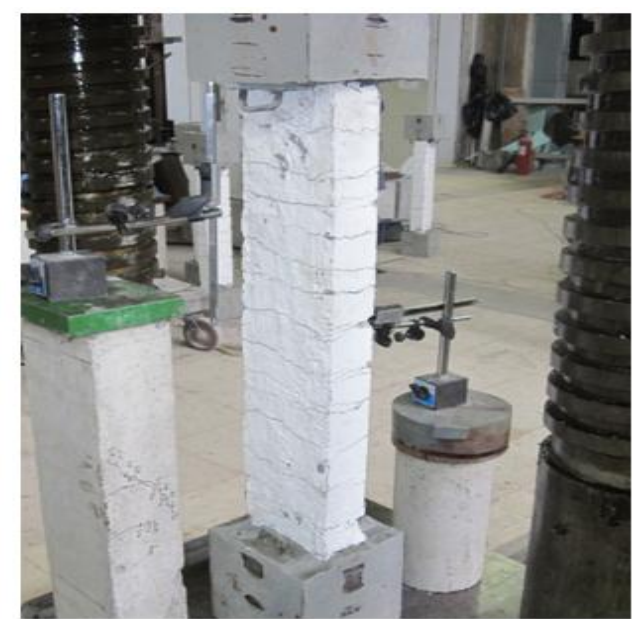

(b)

Figure 2: Test setup for application of: (a) Tensile loading, (b) Compressive loading 


\section{EXPERIMENTAL RESULTS}

Fig. 3 refers to the experiment of uniaxial tension and presents the change of elongation of specimens with respect to the imposed tensile load. It becomes obvious, from a simple observation of the diagram, that the actual degrees of elongation differ a little bit from the nominal degrees of elongation $10 \%, 20 \%, 30 \%$ and $50 \%$. However, in all cases, the differences are small and negligible. Fig. 4 refers to the experiment of concentric compression and presents the change of shortening with respect to the imposed compressive load this time. It becomes, easily, obvious the large drop that exists in the resistance of specimens for the cases of degrees of elongation $30 \%$ and $50 \%$. Finally, Fig. 5 presents the various modes of failure of specimens after the completion of compressive loading. Failure modes are given for all specimens after the end of the compression test.

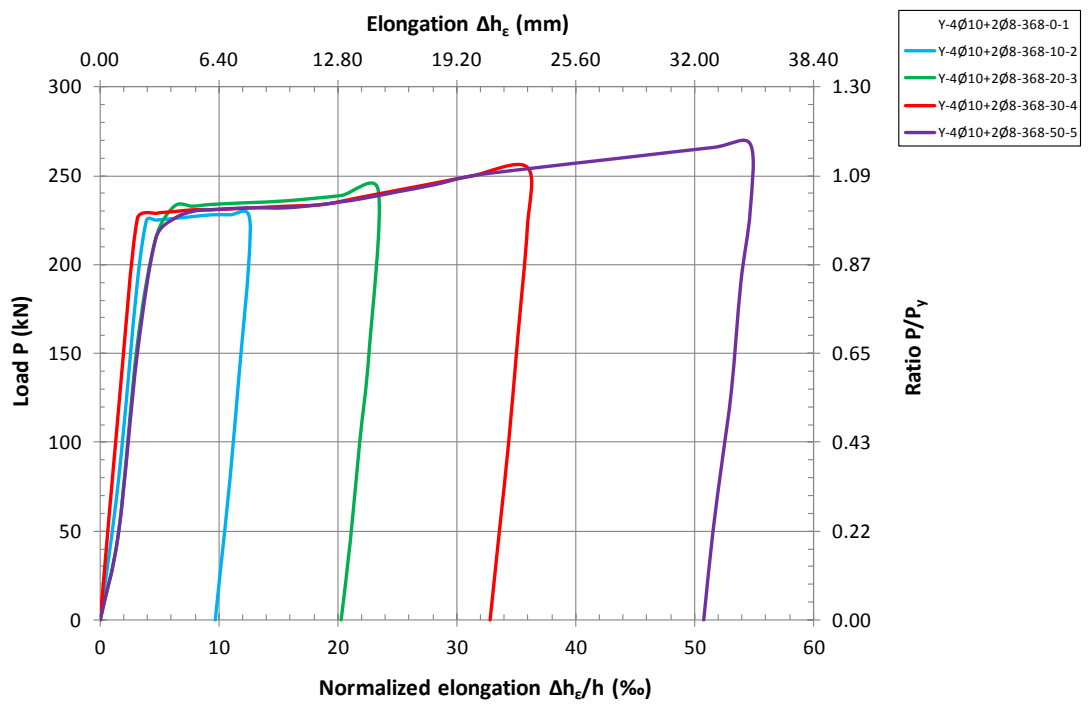

Figure 3: Diagram of tensile load $\left[\mathrm{P}(\mathrm{kN}), \mathrm{P} / \mathrm{P}_{\mathrm{y}}\right]-$ elongation $\left[\Delta \mathrm{h}_{\varepsilon} / \mathrm{h}(\% 0), \Delta \mathrm{h}_{\varepsilon}(\mathrm{mm})\right]$

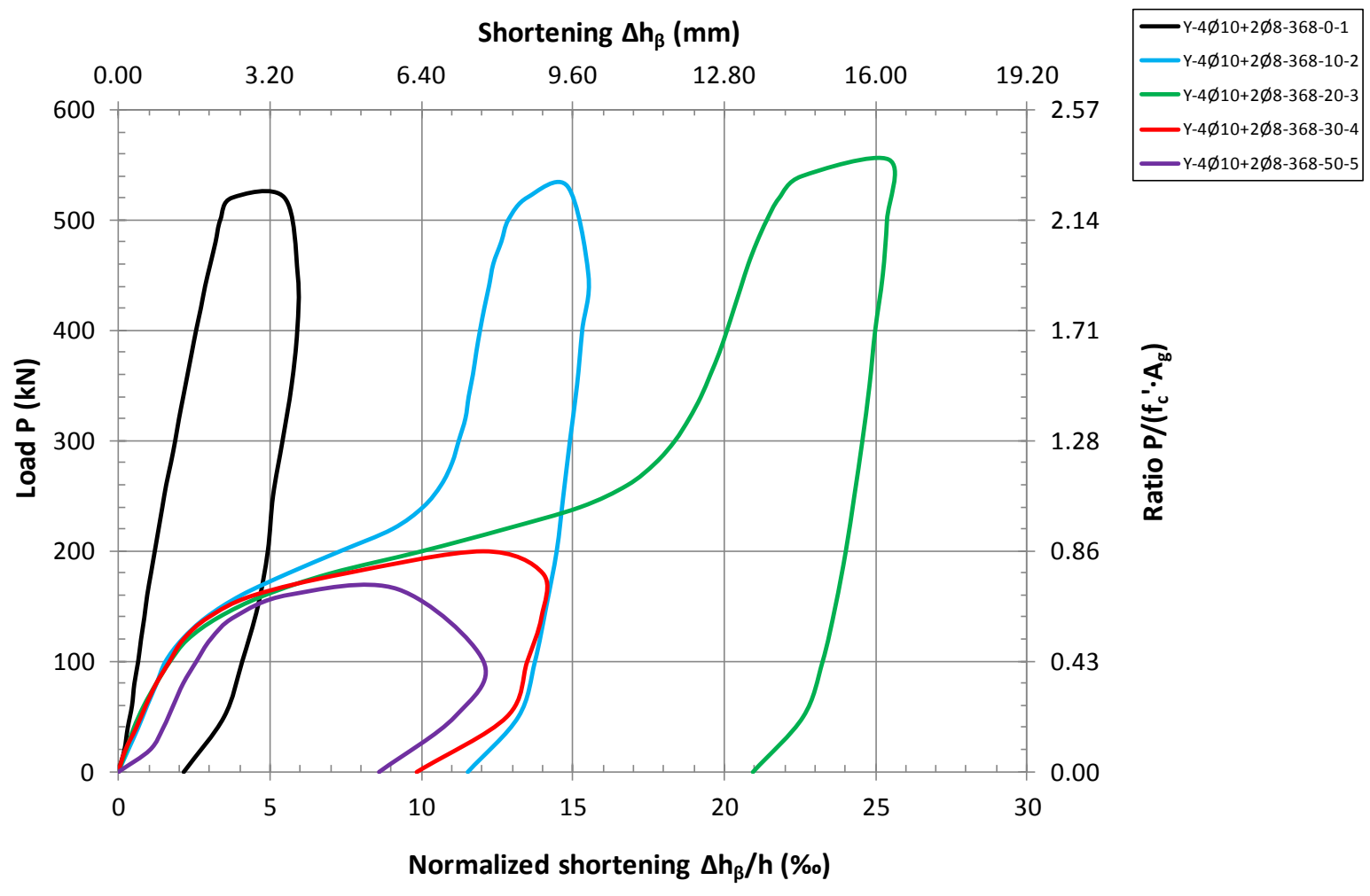

Figure 4: Diagram of compressive load $\left[\mathrm{P}(\mathrm{kN}), \mathrm{P} /\left(\mathrm{f}_{\mathrm{c}}{ }^{\prime} \cdot \mathrm{A}_{\mathrm{g}}\right)\right]-$ shortening $\left[\Delta \mathrm{h}_{\beta} / \mathrm{h}(\% \mathrm{o}), \Delta \mathrm{h}_{\beta}(\mathrm{mm})\right]$ 


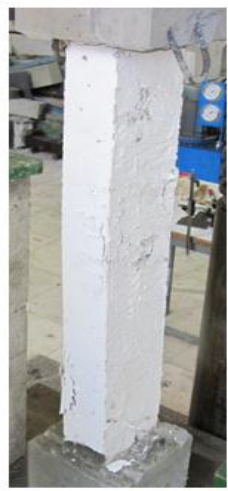

(a)

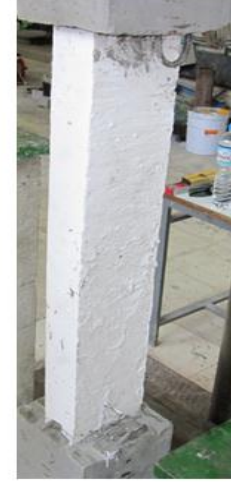

(b)

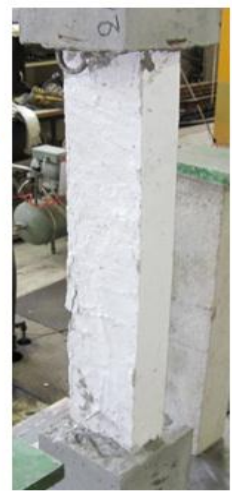

(c)

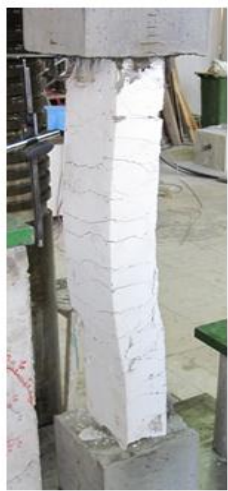

(d)

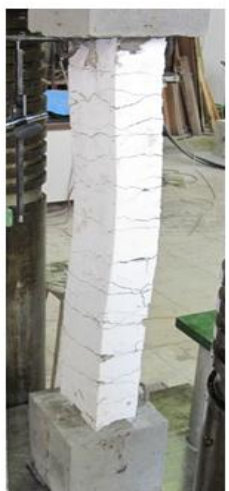

(e)

Figure 5: Failure modes of specimens after the experiment of compression: (a) Y-4Ø10+2Ø8-368-0-1, (b) Y-4Ø10+2Ø8-368-0-2, (c) Y-4Ø10+2Ø8-368-0-3, (d) Y-4Ø10+2Ø8-368-0-4, (e) Y-4Ø10+2Ø8-368-0-5

\section{ANALYSIS Of ReSUlts}

From the conduct of experimental investigation and the evaluation and analysis of test results of specimens, observations arise with regard to the behaviour of test specimens and are the following:

1. For the degrees of elongation $10 \%$ and $20 \%$, the increase of the imposed degree of elongation in the specimens at the first semi-cycle of loading does not cause an important differentiation in the value of maximum failure load at the second semi-cycle of loading, where the compressive loading is applied. Specifically for the degree of elongation $10 \%$, the critical failure load of the specimen equals to the $101 \%$ of the failure load of the equivalent "virgin" specimen (Figs. 6, 7). With regard to the degree of elongation $20 \%$, the critical failure load of the specimen equals to the $106 \%$ of the failure load of the equivalent "virgin" specimen (Figs. 6, 7). It is noted that for the degrees of elongation in question, closure of cracks is realized resulting in the participation of concrete to the resistance of the specimens. Consequently, when an increase of failure load is observed for the degrees of elongation $10 \%$ and $20 \%$ compared to the degree of elongation $0 \%$ ("virgin" specimen), this is believed that it is owed to the instability of the material of concrete with regard to its resistance. It is stressed that conscientious efforts were made so that all specimens, as much as possible, have the same quality of concrete by concreting all specimens together using concrete from the same mixer.

2. For the degrees of elongation $30 \%$ and $50 \%$, the increase of the imposed degree of elongation in the specimens at the first semi-cycle of loading causes reduction of their maximum failure load (resistance of specimens) at the second semi-cycle of loading where the compressive loading is applied. Specifically for the degree of elongation $30 \%$, the critical failure load of the specimen equals to the $38 \%$ of the failure load of the equivalent "virgin" specimen (Figs. 6,7). With regard to the degree of elongation 50\%, the critical load of specimen equals to the $31 \%$ of the failure load of the equivalent "virgin" specimen (Figs. 6, 7). It appears, that is to say, that the increase of the degree of elongation influences considerably the resistance of specimens against transverse instability since a reduction of the order of $60-70 \%$ in the resistance of specimens can take place compared to the specimen that has not undergone any type of tensile loading ("virgin" specimen).

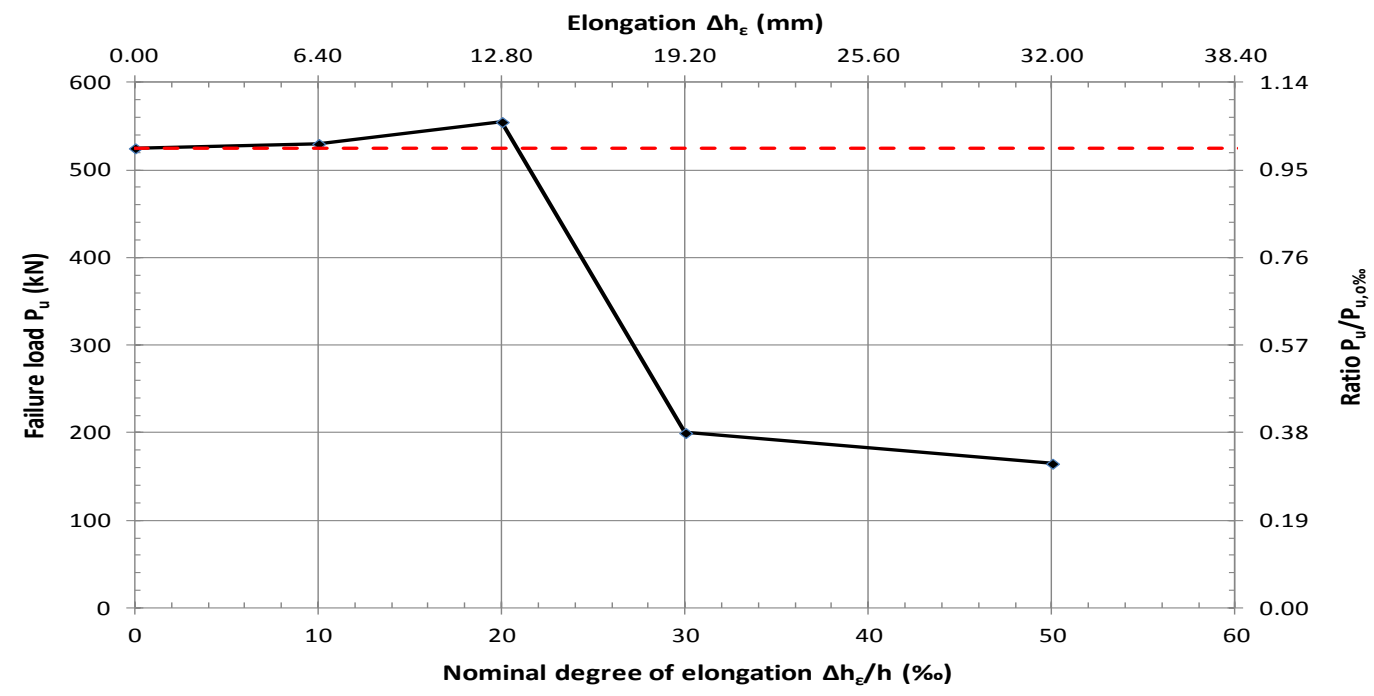

Figure 6: Diagram of maximum failure load $\left[\mathrm{P}_{\mathrm{u}}(\mathrm{kN}), \mathrm{P}_{\mathrm{u}} / \mathrm{P}_{\mathrm{u}, 0 \% 0}\right]-$ elongation $\left[\Delta \mathrm{h}_{\varepsilon} / \mathrm{h}(\%), \Delta \mathrm{h}_{\varepsilon}(\mathrm{mm})\right]$ 


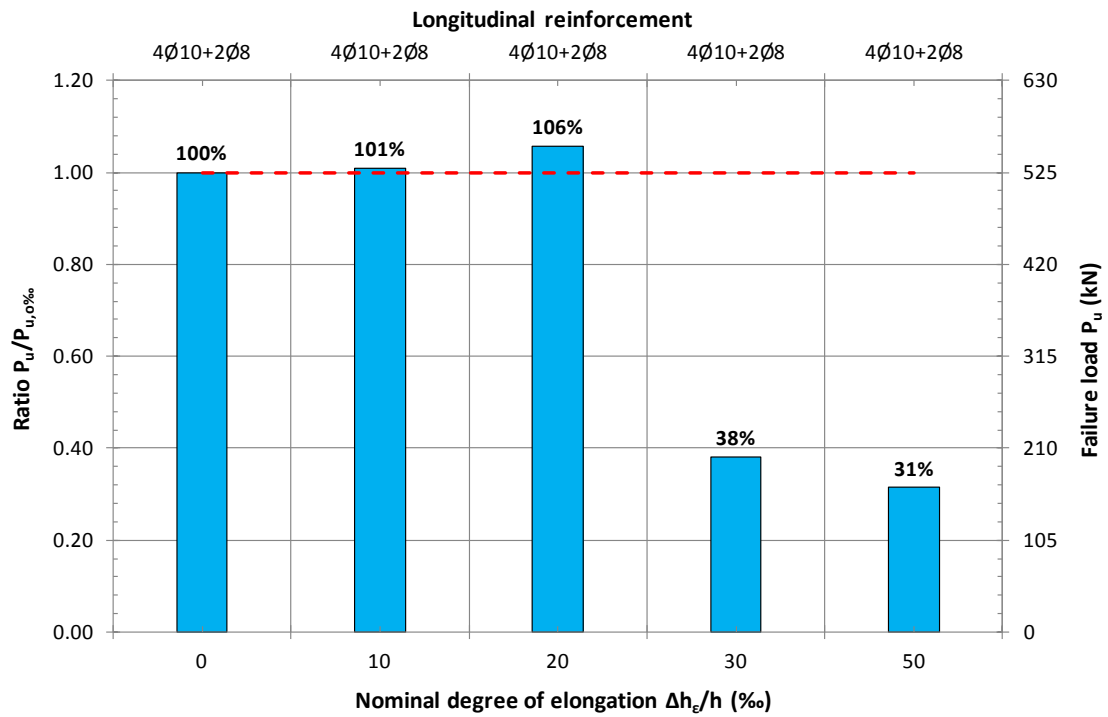

Figure 7: Column diagram of failure load $\left[\mathrm{P}_{\mathrm{u}} / \mathrm{P}_{\mathrm{u}, 0 \%}, \mathrm{P}_{\mathrm{u}}(\mathrm{kN})\right]$ - elongation and type of longitudinal reinforcement $\left[\Delta \mathrm{h}_{\varepsilon} / \mathrm{h}(\%)\right]$

\section{CONCLUSIONS}

Based on the preceded test investigation and analysis and evaluation of its results, the following conclusions arise:

1. It is clearly indicated from the present work that the imposed degree of elongation at the first semi-cycle of tensile loading has catalytic influence, above a certain value, in the maximum failure load at the second semi-cycle of compressive loading.

2. Reduction of maximum capacity due to transverse instability caused by the high degree of elongation imposed at the first semi-cycle of loading can be as much as $60 \%-70 \%$.

3. This fact means that the ultimate bearing capacity of $\mathrm{R} / \mathrm{C}$ seismic walls is influenced tremendously from the imposed tensile strain and since the importance of seismic walls for the safety of a building against earthquake action is well-known, it is suggested that degree of elongation should be taken into account when designing earthquake-resistant structures with a dual structural system.

\section{REFERENCES}

[1] J.W. Wallace, J.P. Moehle, Ductility and detailing requirements of bearing wall buildings, ASCE Journal of Structural Engineering, 116(6), 1992, 1625-1644.

[2] EN 1998-1:2004, Eurocode 8: Design of structures for earthquake resistance - Part 1: General rules, seismic actions and rules for buildings (Brussels, Belgium, European Committee for Standardization, 2004).

[3] NZS 3101:2006, Concrete structures standard: Part 1 - The design of concrete structures (Wellington, New Zealand, Standards New Zealand, 2006).

[4] Greek Concrete Code 2000 (Athens, Greece, O.A.Е.П. / ¿.П.M.Е., 2006)

[5] Y.H. Chai, D.T. Elayer, Lateral stability of reinforced concrete columns under axial reversed cyclic tension and compression, $A C I$ Structural Journal, 96(5), 1999, 780-789.

[6] T. Paulay, The design of ductile reinforced concrete structural walls for earthquake resistance, Earthquake Spectra, 2(4), 1986, 783913.

[7] T. Paulay, M.J.N. Priestley, Stability of ductile structural walls. ACI Structural Journal, 90(4), 1993, 385-392.

[8] T. Chrysanidis, I. Tegos, G. Pallogos, S. Christodoulou, Lateral instability of alternating tensile and compressive flanges of RC shear walls due to intense seismic flexure, Proc. of $3^{\text {rd }}$ Panhellenic Conf. on Earthquake Engineering, Athens, Greece, 2008, ID 1818.

[9] T. Chrysanidis, I. Tegos, V. Gkagkousis, The influence of longitudinal reinforcement ratio of boundary edges of R/C shear walls in their lateral stability, Proc. of $16^{\text {th }}$ Greek Concrete Conference, Pafos, Cyprus, 2009, ID 131005.

[10] T. Chrysanidis, I. Tegos, The influence of the degree of elongation of the longitudinal reinforcement of the high-reinforced end sections of ductile structural walls to their ultimate strength and mode of failure, Proc. of Vienna Congress on Recent Advances in Earthquake Engineering and Structural Dynamics 2013 (VEESD 2013), Vienna, Austria, 2013, ID 181. 